\title{
Association of dietary patterns with BMI and waist circumference in a low-income neighbourhood in Brazil
}

\author{
Diana Barbosa Cunha ${ }^{1}$, Renan Moritz Varnier Rodrigues de Almeida ${ }^{2}$, Rosely Sichieri ${ }^{3}$ \\ and Rosangela Alves Pereira ${ }^{1 *}$ \\ ${ }^{1}$ Department of Nutrition, Federal University of Rio de Janeiro, Avenida Carlos Chagas Filho, 373, Centro de Ciências da Saúde, \\ Bloco J, $2^{\circ}$ andar - sala 10, Cidade Universitária, Rio de Janeiro, RJ 21941-902, Brazil \\ ${ }^{2}$ Program in Biomedical Engineering, Federal University of Rio de Janeiro, Rio de Janeiro, Brazil \\ ${ }^{3}$ Institute of Social Medicine, State University of Rio de Janeiro, Rio de Janeiro, Brazil
}

(Received 4 August 2009 - Revised 9 December 2009 - Accepted 22 February 2010 - First published online 27 April 2010)

Traditional analysis of food intake usually fails to show an association between energy and nutrient intake and indicators of obesity. The analysis of food patterns can contribute to the understanding of the association between eating habits and anthropometric indicators. A population-based cross-sectional study was carried out on a low-income neighbourhood in the Rio de Janeiro metropolitan area, and 1009 subjects between 20 and 65 years of age completed an FFQ. Dietary patterns were identified by means of factor analysis, and their associations with BMI and waist circumference (WC) were ascertained by applying a linear regression analysis. Three main dietary patterns were identified: a mixed pattern, which included cereals, fish and shrimp, vegetables, roots, fruits, eggs, meat and caffeinated beverages; a Western pattern, which consisted of 'fast foods', soft drinks, juices, cakes, cookies, milk and dairy, sweets and snacks; a traditional pattern, which included rice, beans, bread, sugar, fats and salad dressings. After adjusting for age and energy intake, we found that the traditional dietary pattern was inversely associated with BMI $(\beta=-1 \cdot 14$, $P<0.001)$ and WC $(\beta=-14.9, P=0.002)$ among females. Additionally, a positive association between the Western pattern and WC $(\beta=12 \cdot 8$, $P=0.02)$ was observed for females. A diet based on rice and beans may have a protective role against weight gain in women.

Food consumption: Dietary surveys: Factor analysis: Obesity: Overweight

Traditionally, studies on the effect of diet on overweight and obesity have been based on the analysis of energy and nutrient intake $^{(1,2)}$. However, the complexity of the human diet is a limiting factor for this type of approach, since people usually ingest vastly different types of foods. Thus, the effect of specific food components cannot be easily identified, and it is reasonable to assume the occurrence of an interactive combination of these in any $\operatorname{diet}^{(3,4)}$.

Statistical procedures, such as factor and cluster analyses, have been used for the identification of dietary patterns for more than 20 years as a means of identifying at-risk population subgroups. These methods allow for the development of dietary recommendations and guidelines that can be justified in more rational terms ${ }^{(5,6)}$, as the identified patterns can be a proxy of the real food availability conditions and provide a more realistic representation of the eating habits of a studied population ${ }^{(7)}$. These analyses can be particularly important when dealing with underprivileged segments of large urban populations ${ }^{(8,9)}$, who are at increased risk of becoming obese in most countries ${ }^{(10)}$.

In Brazil, Household Budget Surveys developed between 1970 and 2003 have evidenced important shifts in eating habits. The availability of traditional foods such as pulses, rice, vegetables and fruits has decreased, whereas the intake of industrialised cookies and sodas increased by as much as $400 \%{ }^{(11)}$. These changes have been identified in studies that analysed eating patterns considering individual food intake. Sichieri et al. ${ }^{(12)}$. observed that two eating patterns prevailed in urban areas in the Brazilian Northeast and Southeast in 1996-7: the mixed pattern, which included an array of diverse foods, and the traditional pattern, which was strongly based on rice and beans. In a hospital-based case-control study on oral cancer, Marchioni et al. ${ }^{(13)}$ analysed data from 260 cases and 257 controls in São Paulo from 1998 to 2001. These authors identified three eating patterns: prudent (characterised by the intake of fruits, vegetables and meat); traditional (including cereals and pulses); snacks (mainly composed of sweets, dairy and processed meat).

In Brazil, the prevalence of excessive weight is rising, and it reached approximately $50 \%^{(14)}$ in $2002-3$; it is thus the most serious nutritional problem in the country. Studies on the role of the different eating habits in the development of excessive weight gain and obesity are needed in order to appropriately define nutritional and food guidance for different groups of the population. Therefore, this work aimed to identify eating patterns and to explore their associations with the variations

Abbreviation: WC, waist circumference.

* Corresponding author: Dr Rosangela Alves Pereira, fax +55 212280 8343, email roapereira@ufrj.br 
in anthropometric indicators of excessive weight among low-income adults from the metropolitan region of Rio de Janeiro, Brazil.

\section{Methods and procedures}

\section{Study design and setting}

Data that are reported were obtained from a population-based cross-sectional study that was conducted in 2005 in the district of Campos Elíseos in the municipality of Duque de Caxias, which is located in the Rio de Janeiro metropolitan area (Rio de Janeiro State, Brazil). Campos Elíseos is one of the poorest districts in the region, and there were 244000 inhabitants in $2000^{(15)}$.

Subjects in the present study were adults aged 19-65 years who lived in permanent private residences in the study area. The sample design consisted of three stages of sampling: census tracts, houses and individuals. Initially, seventy-five census tracts (out of the original 322) were selected. A total of fifteen households were selected in each of these, resulting in a total of 1125 residences. Inside each census tract, households were ranked according to income, allowing for systematic sampling of individuals according to this variable. Finally, individuals in each household were randomly selected.

Food intake was assessed by a previously validated ${ }^{(16)}$ semi-quantitative FFQ administered by interview. This questionnaire included eighty-two food items, their respective reference portions and eight options for reporting the frequency of intake during the preceding year.

Subjects' weights were measured using a digital scale with a maximum capacity of $150 \mathrm{~kg}$ and a precision of $100 \mathrm{~g}$ (Plenna ${ }^{\circledR}$, São Paulo, Brazil). They were weighed while barefoot, wearing light clothing and standing at the centre of the scale, with arms hanging alongside the body. Height was measured using a portable stadiometer with a maximum range of $200 \mathrm{~cm}$ and a precision of $0.1 \mathrm{~cm}$ (model 206; Seca ${ }^{\circledR}$, Hamburg, Germany) ${ }^{(17)}$. An inelastic tape with a maximum length of $150 \mathrm{~cm}$ and a precision of $0 \cdot 1 \mathrm{~cm}$ was used for the measurement of waist circumference (WC). The BMI (weight/height ${ }^{2}$ ) was calculated. Overweight was defined as a BMI in the range of $25-29.9 \mathrm{~kg} / \mathrm{m}^{2}$, and obesity was defined as a $\mathrm{BMI} \geq 30 \mathrm{~kg} / \mathrm{m}^{2(18)}$. Following the procedures suggested by Callaway et $a l .^{(19)}$, the WC was double-measured at the point of minimum abdominal circumference. A maximum variation of $0.5 \mathrm{~cm}$ was accepted between the two waist measurements; when a larger difference was found, both the measurements were repeated. The mean of the two valid measurements was used as the final WC value ${ }^{(19)}$.

The present study was conducted according to the Declaration of Helsinki guidelines, and all procedures involving human subjects/patients were approved by the Ethics Committee of the Institute of Social Medicine (State University of Rio de Janeiro, Brazil). Written informed consent was obtained from all the subjects.

\section{Statistical analysis}

The eighty-two food items in the FFQ were transformed into daily consumption frequencies and were then collapsed into
Table 1. Food groups and food items from a semi-quantitative FFQ given to 1009 subjects living in a low socio-economic neighbourhood in the Rio de Janeiro metropolitan area (Rio de Janeiro, Brazil)

\begin{tabular}{|c|c|}
\hline Groups & Foods \\
\hline Cereals & Polenta, maize and spaghetti \\
\hline Bread & French bread or loaf bread \\
\hline Rice & Rice \\
\hline Beans & Black beans \\
\hline Fish and shrimps & Fresh fish, shrimps, sardines and tuna fish \\
\hline Vegetables & $\begin{array}{l}\text { Chayote, okra, cucumber, beets, carrots, } \\
\text { onion, garlic, peppers, tomatoes, zucchini, } \\
\text { pumpkin and green beans }\end{array}$ \\
\hline Leafy vegetables & Cauliflower, lettuce, cabbage and chicory \\
\hline Roots & $\begin{array}{l}\text { Manioc, cassava flour, yams and baked } \\
\text { potatoes }\end{array}$ \\
\hline Fruits & $\begin{array}{l}\text { Orange, tangerine, banana, pears, pineapple, } \\
\text { apples, guava, melon or watermelon, } \\
\text { avocado, mango, passion fruit and grapes }\end{array}$ \\
\hline Juices & Fruit juices \\
\hline Cakes and biscuits & Cakes and biscuits (salted or sweet) \\
\hline Soft drinks & Soft drinks \\
\hline Milk and dairy & $\begin{array}{l}\text { Milk, yogurt, cheese, cream cheese and } \\
\text { other dairy }\end{array}$ \\
\hline Meat & $\begin{array}{l}\text { Chicken, beef, ground beef, pork, hamburger } \\
\text { and offals }\end{array}$ \\
\hline Eggs & Eggs \\
\hline Sausages & Sausages \\
\hline Caffeinated beverages & Yerba matte and coffee \\
\hline Sweets & $\begin{array}{l}\text { Caramels, ice cream, pudding, flan, other } \\
\text { sweets and chocolate in powder form } \\
\text { or in bars }\end{array}$ \\
\hline Sugar & Sugar \\
\hline Snacks and fast food & $\begin{array}{l}\text { Fried chips, other salty snacks, pizza and } \\
\text { popcorn }\end{array}$ \\
\hline Dressings and fats & Mayonnaise, bacon, butter or margarine \\
\hline
\end{tabular}

twenty-one food groups, taking into account their nutritional characteristics and consumption frequencies (Table 1).

Factor analysis and principal component analysis were used to identify the eating patterns. In factor analysis, a smaller set of variables (known as 'factors', 'components' or, in the case of the present study, 'patterns') are extracted from the correlation structure of a given set of variables. In the present study, the set of variables used to extract the factors were the twentyone food groups. The procedure generated factor loadings for each food group related to each dietary pattern extracted. The factor loadings measure the correlation between the identified dietary pattern and the food groups. Larger factor loading values indicate a greater contribution of that food group to the dietary pattern. The identified factors (or patterns) are able to represent the variance of the original data ${ }^{(20)}$.

The Bartlett Test of Sphericity and the Kaiser-MeyerOlkin Measure of Sampling Adequacy were used to assess data adequacy for factor analysis. Factors were rotated by the Varimax procedure to improve the interpretation of the results. Retention of factors was based on the scree test ${ }^{(21)}$. Food items were retained in the pattern if the factor loading value was equal to or above $0 \cdot 30$, and the least acceptable communality (i.e. the proportion of variance of each variable that could be explained by the factors) was $0 \cdot 25^{(20)}$. The internal consistency of the detected factors was further assessed using the Cronbach $\alpha$ index, and values above 0.60 were considered acceptable ${ }^{(20)}$. Patterns were named according to their interpretation and food items included. 
There was no substantial difference in the dietary patterns by sex, so analyses were performed for both men and women combined to maximise the statistical power. Interactions between food patterns and sex were also tested in the regression analysis.

The association between nutritional patterns and BMI and WC was analysed using linear regression models. Independent variables included the factor scores of the identified food patterns, whereas confounding covariates comprised (a) age in years as a continuous variable, (b) education in years of study as a continuous variable, (c) cigarette smoking (categorised as current smokers, ex-smokers and non-smokers) and (d) level of physical activity (classified as light, moderate or intense, according to the frequency of physical activity involved in leisure, work and domestic activities as well as of physical activity related to moving to and from work or school). Because total energy intake may affect BMI and WC, it is arguable whether energy intake should be included in these models; nevertheless, we fit a model for each analysis having total energy intake as a covariate to see whether this adjustment would change our estimates. Frequency histograms were used to assess data normality. All analyses were performed with SPSS - Statistical Package for Social Sciences - 13.0 software (SPSS, Inc., Chicago, IL, USA).

\section{Results}

From a total of 1253 eligible subjects, 222 subjects $(17.7 \%)$ were excluded due to reporting of less plausible energy intakes (i.e. below $2100 \mathrm{~kJ}(500 \mathrm{kcal}))$ per day $(n 5)$ or above $25200 \mathrm{~kJ}$ (or $6000 \mathrm{kcal}$ ) per day (n 217)). Additionally, twenty-two subjects $(1.8 \%)$ were excluded due to missing anthropometric data. Therefore, the analysis was performed on 1009 individuals (males: $34 \%, n$ 339, and females: $66 \%, n$ 670). These subjects had an average age of 38.7 years (SD 11.97). The overall prevalence of being overweight was $34.9 \%$, without any statistically significant sex differences. The overall prevalence of obesity was $19.1 \%(12.3 \%$ for men and $22.4 \%$ for women; $P=0 \cdot 001$ ).

Both the Kaiser-Meyer-Olkin index (0.75) and Bartlett's test $(P<0.01)$ indicated that the correlation among the variables was sufficiently strong for a factor analysis. Scree test results allowed for the identification of three dietary patterns with eigenvalues equal to 3.42 (mixed), 2.11 (Western) and 1.79 (traditional). The mixed pattern (loading heavily on cereals, fish and shrimps, leafy greens, vegetables, roots, meat, eggs, sausage and caffeinated beverages) explained $16.3 \%$ of the data variation. The Western pattern (consisting of fast foods, soft drinks, juice, milk and dairy, sweets, cakes and cookies) explained $10.0 \%$ of the data variation. The traditional pattern (consisting of rice and beans, bread, sugar, salad dressings and fats) explained $8.5 \%$ of the total variation. Together, the three factors explained $34.9 \%$ of the dietary intake variance.

All the food groups were associated with one of the identified patterns. Although one item (sugar) presented a communality value below the critical $0 \cdot 25$ threshold, it was still kept in the analysis since it is a food important for the intake of energy. Furthermore, the dependent variables (BMI and WC) are related to energy balance. The additional indicators of internal consistency were also acceptable (Table 2).
Table 2. Food patterns, factor loads and communalities $\left(h_{2}\right)$ resulting from a factor analysis with 1009 subjects living in a low socio-economic neighbourhood in the Rio de Janeiro metropolitan area (Rio de Janeiro, Brazil)

\begin{tabular}{|c|c|c|c|c|}
\hline \multirow[b]{2}{*}{ Food groups } & \multicolumn{3}{|c|}{ Patterns } & \multirow[b]{2}{*}{$h_{2}$} \\
\hline & Mixed & Western & Traditional & \\
\hline Cereals & 0.38 & & & 0.25 \\
\hline Bread & & & 0.50 & 0.36 \\
\hline Rice & & & 0.67 & 0.47 \\
\hline Beans & & & 0.66 & 0.45 \\
\hline Fish and shrimps & 0.59 & & & 0.40 \\
\hline Vegetables & 0.65 & & & 0.48 \\
\hline Leafy vegetables & 0.65 & & & 0.54 \\
\hline Roots & 0.54 & & & 0.32 \\
\hline Fruits & 0.49 & & & 0.47 \\
\hline Juices & & 0.45 & & 0.23 \\
\hline Cakes and biscuits & & 0.48 & & 0.24 \\
\hline Soft drinks & & 0.51 & & 0.27 \\
\hline Milk and dairy & & 0.62 & & 0.41 \\
\hline Meat & 0.52 & & & 0.43 \\
\hline Eggs & 0.40 & & & 0.21 \\
\hline Sausage & 0.48 & & & 0.28 \\
\hline Caffeinated beverages & 0.36 & & & 0.23 \\
\hline Sweets & & 0.70 & & 0.53 \\
\hline Sugar & & 0.33 & & 0.11 \\
\hline Snacks and fast food & & 0.53 & & 0.37 \\
\hline Salad dressing and fats & & & 0.46 & 0.28 \\
\hline Eigenvalues & 3.42 & $2 \cdot 11$ & 1.79 & \\
\hline$\%$ of explained variance & $16 \cdot 27$ & $10 \cdot 05$ & 8.53 & \\
\hline $\begin{array}{l}\% \text { of accumulated explained } \\
\text { variance }\end{array}$ & $16 \cdot 27$ & $26 \cdot 32$ & $34 \cdot 86$ & \\
\hline
\end{tabular}

Table 3 shows that the traditional pattern was inversely associated with both BMI $(\beta=-1 \cdot 15, P<0 \cdot 01)$ and WC $(\beta=-20.86, \quad P<0.01)$ among women. This relationship was statistically significant even after adjusting for age, education, cigarette smoking, physical activity and energetic consumption (BMI: $\beta=-1 \cdot 12, \quad P<0.01$ and WC: $\beta=-14.68, P=0.003)$. The association of the Western pattern with BMI and WC was also identified among women, even after adjusting for age, education, cigarette smoking, physical activity and energetic consumption (BMI: $\beta=0.74$, $P=0.02$ and WC: $\beta=13.61, P=0.02$ ).

\section{Discussion}

Three dietary patterns (mixed, Western and traditional) were identified among adults living in an urban, low socioeconomic status area in Brazil. The traditional pattern, characterised by the consumption of basic staple foods (e.g. rice and beans), had a protective effect on BMI and WC among women. Additionally, the Western pattern, which mainly consisted of fast food, sweets and sweetened beverages, was positively associated with WC and BMI among females. A lack of association between any of the identified dietary patterns and BMI and WC among men was also observed. This is probably because of the lower prevalence of obesity among men than among women, since the food patterns were similar for both the groups. These findings depict the significant variability in food intake observed among the studied population, and contribute to the understanding of the dietary profile of population groups living in the periphery of highly urbanised metropolitan areas of the country. 
Table 3. Regression models for the association between food patterns and BMI/ waist circumference (WC) among 1009 subjects living in a low socio-economic neighbourhood in the Rio de Janeiro metropolitan area (Rio de Janeiro, Brazil)

(Regression and probability values)

\begin{tabular}{|c|c|c|c|c|}
\hline \multirow[b]{2}{*}{ Dietary pattern } & \multicolumn{2}{|c|}{ Males } & \multicolumn{2}{|c|}{ Females } \\
\hline & $\beta$ & $P$ & $\beta$ & $P$ \\
\hline Models & \multicolumn{4}{|c|}{ BMI $\left(\mathrm{kg} / \mathrm{m}^{2}\right)$} \\
\hline Mixed & & & & \\
\hline 0 & -0.19 & 0.358 & 0.38 & 0.157 \\
\hline 1 & -0.19 & 0.358 & 0.33 & 0.223 \\
\hline 2 & -0.06 & 0.795 & 0.43 & 0.137 \\
\hline \multicolumn{5}{|l|}{ Western } \\
\hline 0 & -0.15 & 0.482 & 0.07 & 0.777 \\
\hline 1 & -0.10 & 0.670 & 0.48 & 0.088 \\
\hline 2 & 0.13 & 0.599 & 0.74 & 0.022 \\
\hline \multicolumn{5}{|l|}{ Traditional } \\
\hline 0 & -0.53 & 0.024 & $-1 \cdot 15$ & $<0.001$ \\
\hline 1 & -0.33 & 0.164 & $-1 \cdot 12$ & $<0.001$ \\
\hline \multirow[t]{2}{*}{2} & -0.24 & 0.320 & $-1 \cdot 12$ & $<0.001$ \\
\hline & \multicolumn{4}{|c|}{ WC (cm) } \\
\hline \multicolumn{5}{|l|}{ Mixed } \\
\hline 0 & $3 \cdot 38$ & 0.539 & $6 \cdot 50$ & 0.199 \\
\hline 1 & -0.29 & 0.958 & $3 \cdot 62$ & 0.450 \\
\hline 2 & -0.53 & 0.928 & 5.24 & 0.301 \\
\hline \multicolumn{5}{|l|}{ Western } \\
\hline 0 & -3.84 & 0.507 & -5.40 & 0.273 \\
\hline 1 & 4.65 & 0.430 & 8.66 & 0.078 \\
\hline 2 & $5 \cdot 68$ & 0.397 & $13 \cdot 61$ & 0.016 \\
\hline \multicolumn{5}{|l|}{ Traditional } \\
\hline 0 & $-12 \cdot 36$ & 0.047 & $-20 \cdot 86$ & $<0.001$ \\
\hline 1 & $-6 \cdot 15$ & 0.314 & -14.88 & 0.003 \\
\hline 2 & $-6 \cdot 62$ & 0.292 & -14.68 & 0.003 \\
\hline
\end{tabular}

Model 0 , crude; Model 1 , adjusted by age, education, cigarette smoking and physical activity; Model 2, Model 1 + energy intake.

Other studies in Brazil found dietary patterns similar to the traditional pattern described ${ }^{(12,13,22)}$, and these studies also observed an inverse association of this pattern with $\mathrm{BMI}^{(12,22)}$. A possible explanation for the protective role of the traditional pattern is the low glycaemic index of this food combination. Sugiyama et al. ${ }^{(23)}$ demonstrated that the combination of rice and beans has a lower glycaemic index than rice alone, which could justify the inverse relationship between the traditional pattern and WC observed in the present study. In addition, the protective effect of dietary fibre on excess body weight has been shown in several studies $^{(24-26)}$, and the high fibre content of beans ${ }^{(26)}$ is one of the reasons for recommending the consumption of this food in many dietary guidelines ${ }^{(27-29)}$. The reduced variety of food items observed in the traditional pattern may play a role in BMI reduction. An 18-month controlled trial among Brazilian women did not demonstrate a protective role of the traditional diet ${ }^{(30)}$, suggesting that the monotonousness of the diet (more than the dietary pattern) was the mechanism behind the diet's protective effect against weight gain. It is reasonable to hypothesise that the absence of an effect of the mixed pattern on BMI and WC may be related to the monotonousness $v$. diversity hypothesis.

On the other hand, a traditional diet, also containing rice and beans, of Puerto Ricans was associated with the presence of the metabolic syndrome. In Puerto Rico, however, the highest factor loading for this diet was attributed to oils (0.77); the second highest was attributed to rice (0.76), with beans receiving a lower factor loading $(0.55)^{(31)}$. In the Brazilian traditional diet, in contrast, beans and rice had similar factor loadings (0.66 and 0.67), whereas fats had a smaller loading (0.46). Moreover, the consumption of these foods appears to be a marker of a more consistently home-prepared diet, with lower consumption of processed foods and less frequent outof-home eating; these trends result in a reduced intake of fats and high-energy-dense foods. In Brazil, the consumption of foods away from home is highly associated with the consumption of soft drinks, deep-fried snacks and sweets, as shown in an analysis of the 2002-3 Household Budget Survey. Even though soft drinks and sit-down meals had the highest frequencies of consumption away from home, sit-down meals were the most expensive and probably not common among low-income segments of the population ${ }^{(32)}$.

Other studies also found a pattern similar to the Western pattern observed in the present study. In these studies, this pattern usually included red meat, sweets, desserts, foods containing high fat content and/or processed cereal and sometimes eggs, dairy products and sweetened beverages $(3,33,34)$. Such food components have been associated with metabolic problems due to their high levels of fat, $\mathrm{Na}$ and sugar ${ }^{(34-37)}$, and these components are also well known to be associated with weight gain. For instance, the Nurses' Health Study II, which followed 51670 nurses in the USA between 1991 and 1999, identified that a dietary pattern composed of processed meats, cereals, potatoes, sweets and desserts was associated with weight gain $^{(34)}$. Moreover, a case-control analysis of women with breast cancer ${ }^{(36)}$ found that adherence to a Westernised pattern (whole dairy products, processed cereals, salad dressings, fats, fast food, bacon, sausage, red meat and sugar) was associated with both being overweight and obesity, even after controlling for age, physical activity, race and energetic consumption.

In the present study, the pattern that included healthy foods also included sausages and red meat, which are not considered healthy; for this reason, this pattern was designated as mixed. The association between the mixed pattern and the increase in anthropometric indicators may be related to reverse causation, as it is possible that subjects concerned with excessive body weight choose to eat low-energy foods such fish, fruits and vegetables.

Other studies have also identified similar 'mixed' patterns, usually including the consumption of cereals, meats, eggs, fruits, fish, caffeinated beverages and vegetables ${ }^{(22,38-40)}$. These studies observed that these mixed patterns were inversely associated with WC and blood pressure ${ }^{(40)}$, and that the subjects with BMI in the range of $20-24.9 \mathrm{~kg} / \mathrm{m}^{2}$ had higher factor loadings for the so-called mixed pattern ${ }^{(38)}$. The mixed pattern found in the present study shares common components with 'prudent' or 'healthy' patterns identified in other studies ${ }^{(3,33,34,41-44)}$. In these studies, a clear pattern including vegetables, fruits and fish could be detected; four of them also included chicken ${ }^{(3,34,41,42)}$, three observed cereal ingestion $^{(3,34,43)}$, and one included eggs ${ }^{(42)}$.

The limitations of the present study are related to the crosssectional study design, which does not allow observation of the effect of independent variables and instead only permits association of independent and dependent variables. Additionally, the factor analysis encompasses several 
decisions that were made arbitrarily (e.g. decision to include the variables in the patterns). Such conditions undermine the comparability of the present study with other studies. Considering the similarity between the food groups included in the analysis and magnitude of the factor loadings, such a comparison should be established. Moreover, the results obtained with factor analysis are not easily translated to the individual level as this method attributes factor scores based on the correlations between the food groups ${ }^{(45)}$.

The present study was useful in providing a better understanding of the nutritional habits of the studied population, and therefore, offering insights into the possibilities of intervention for groups at risk of becoming overweight or experiencing obesity or metabolic disorders. The associations observed in women support the current recommendations that (1) promote the regular intake of the traditional Brazilian diet based on the 'rice and beans' combination, and (2) discourage the intake of high-energy-dense foods. This is especially important given the evidence that changes in food availability are taking place in the country. These changes include the large-scale introduction of high-energy-dense foods and the reduced availability of beans, and they can be considered as components of the nutritional transition process. Such changes are certainly one of the factors related to the increase in excessive weight rates.

In conclusion, the present study identified three dietary patterns that were internally consistent and comparable to those identified in analogous studies carried out in Brazil. Among women, we suggest that a diet based on rice and beans may have a protective role against weight gain. In addition, the mixed pattern was associated with increases in both BMI and $\mathrm{WC}$, although the possibility of reverse causality remains.

\section{Acknowledgements}

We thank the National Council for Scientific and Technological Development of Brazil (CNPq) (grant no. 503139 2003-3), the Brazilian National Cancer Institute (INCA) for the research financial support and the CAPES (Coordenação de Aperfeiçoamento de Pessoal de Nível Superior), which supported one of the authors (D. B. C.) during her Masters studies. The authors declare that there is no conflict of interest. The contributions of the authors are as follows: D. B. C. was involved in study design, data management, statistical analysis and interpretation, and manuscript design and writing. R. S. was involved in study design and supervision, data analysis and data interpretation. R. M. V. R. d. A. was involved in data analysis, data interpretation and manuscript writing. R. A. P. was involved in study design and supervision, data management, analysis and interpretation, and manuscript design and writing.

\section{References}

1. Rocandio AM, Ansotegui L \& Arroyo M (2001) Comparison of dietary intake among overweight and non-overweight schoolchildren. Int J Obes 25, 1651-1655.

2. Andrade RG, Pereira RA \& Sichieri R (2003) Food intake in overweight and normal-weight adolescents in the city of Rio de Janeiro. Cad Saude Publica 19, 1485-1495.
3. Fung TT, Rimm EB, Spiegelman D, et al. (2001) Association between dietary patterns and plasma biomarkers of obesity and cardiovascular disease risk. Am J Clin Nutr 73, $61-67$.

4. Jacques PF \& Tucker KL (2001) Are dietary patterns useful for understanding the role of diet in chronic disease? Am J Clin Nutr 73, 1-2.

5. Correa Leite ML, Nicolosi A, Cristina S, et al. (2003) Dietary and nutritional patterns in an elderly rural population in Northern and Southern Italy: (II). Nutritional profiles associated with food behaviours. Eur J Clin Nutr 57, 1522-1529.

6. Wirfalt E, Hedblad B, Gullberg B, et al. (2001) Food patterns and components of the metabolic syndrome in men and women: a cross-sectional study within the Malmo Diet and Cancer cohort. Am J Epidemiol 154, 1150-1159.

7. Hu FB (2002) Dietary pattern analysis: a new direction in nutritional epidemiology. Curr Opin Lipidol 13, 3-9.

8. Lin H, Bermudez OI \& Tucker KL (2003) Dietary patterns of Hispanic elders are associated with acculturation and obesity. J Nutr 133, 3651-3657.

9. Newby PK, Muller D, Hallfrisch J, et al. (2003) Dietary patterns and changes in body mass index and waist circumference in adults. Am J Clin Nutr 77, 1417-1425.

10. Monteiro CA, Conde WL \& Popkin BM (2007) Income-specific trends in obesity in Brazil: 1975-2003. Am J Public Health 97, $1808-1812$.

11. Levy-Costa RB, Sichieri R, Pontes Ndos S, et al. (2005) Household food availability in Brazil: distribution and trends (1974-2003). Rev Saude Publica 39, 530-540.

12. Sichieri R, Castro JF \& Moura AS (2003) Factors associated with dietary patterns in the urban Brazilian population. Cad Saude Publica 19, Suppl. 1, S47-S53.

13. Marchioni DM, Latorre Mdo R, Eluf-Neto J, et al. (2005) Identification of dietary patterns using factor analysis in an epidemiological study in Sao Paulo. Sao Paulo Med J 123, $124-127$.

14. IBGE - Instituto Brasileiro de Geografia e Estatística (2004) National Household Budget Survey 2002-2003: Analyses on Household Food Availability and Nutrition Status in Brazil (in Portuguese). IBGE: Rio de Janeiro.

15. IBGE - Instituto Brasileiro de Geografia e Estatística (2000) Demographic Census. IBGE: Rio de Janeiro.

16. Sichieri R \& Everhart J (1998) Validity of a Brazilian food frequency questionnaire against dietary recalls and estimated energy intake. Obes Res 18, 1649-1659.

17. Gordon CC, Chumlea WC \& Roche TG (1988) Stature, recumbent length, and weight. In Anthropometric Standardization Reference Manual, pp. 3-8 [TG Lohman, AF Roche and R Martorel, editors]. Champaign, IL: Human Kinetics Books.

18. WHO (1990) Diet, Nutrition, and the Prevention of Chronic Diseases. Geneva: World Health Organization.

19. Callaway CW, Chumlea WC, Bouchard C, et al. (1988) Circumferences. In Anthropometric Standardizing Reference Manual, pp. 39-54 [TG Lohman, AF Roche and R Martorel, editors]. Champaign, IL: Human Kinetics Inc.

20. Basilevsky AT (1994) Statistical Factor Analysis and Related Methods - Theory and Application. New York: Wiley Interscience.

21. Cattel R (1966) The screen test for the number of factors. Multivariate Behav Res 1, 245-276.

22. Sichieri R (2002) Dietary patterns and their associations with obesity in the Brazilian city of Rio de Janeiro. Obes Res 10, $42-48$.

23. Sugiyama M, Tang AC, Wakaki Y, et al. (2003) Glycemic index of single and mixed meal foods among common Japanese foods with white rice as a reference food. Eur J Clin Nutr 57, 743-752. 
24. Slavin JL (2005) Dietary fiber and body weight. Nutrition 21, 411-418.

25. Liu S, Willett WC, Manson JE, et al. (2003) Relation between changes in intakes of dietary fiber and grain products and changes in weight and development of obesity among middleaged women. Am J Clin Nutr 78, 920-927.

26. Howarth NC, Saltzman E \& Roberts SB (2001) Dietary fiber and weight regulation. Nutr Rev 59, 129-139.

27. Brasil, Ministério da Saúde (2006) Guia alimentar para a população brasileira: promovendo a alimentação saudável (Food Guide for the Brazilian Population: promoting Healthy Eating). Brasília: Secretaria de atenção à saúde. pp. 210.

28. Department of Health and Human Services (HHS) and Department of Agriculture (USDA) (2005) Dietary Guidelines for Americans. Washington, DC: United States Department of Agriculture.

29. Department of Health and Human Services (HHS) and Department of Agriculture (USDA) (2001) The Food Guide Pyramid. Washington, DC: United States Department of Agriculture.

30. Sichieri R, Moura AS, Genelhu V, et al. (2007) An 18-mo randomized trial of a low-glycemic-index diet and weight change in Brazilian women. Am J Clin Nutr 86, 707-713.

31. Noel SE, Newby PK, Ordovas JM, et al. (2009) A traditional rice and beans pattern is associated with metabolic syndrome in Puerto Rican older adults. J Nutr 139, 1360-1367.

32. Bezerra IN \& Sichieri R (2009) Eating out of home and obesity: a Brazilian nationwide survey. Public Health Nutr 12, 2037-2043.

33. Paradis AM, Perusse L \& Vohl MC (2006) Dietary patterns and associated lifestyles in individuals with and without familial history of obesity: a cross-sectional study. Int J Behav Nutr Phys Act 3, 38.

34. Schulze MB, Fung TT, Manson JE, et al. (2006) Dietary patterns and changes in body weight in women. Obesity (Silver Spring) 14, 1444-1453.

35. Heidemann C, Schulze MB, Franco OH, et al. (2008) Dietary patterns and risk of mortality from cardiovascular disease, cancer, and all causes in a prospective cohort of women. Circulation 118, 230-237.

36. Murtaugh MA, Herrick JS, Sweeney C, et al. (2007) Diet composition and risk of overweight and obesity in women living in the southwestern United States. J Am Diet Assoc 107, 1311-1321.

37. Hoffmann K, Blaudszun J, Brunken C, et al. (2005) Lipid class distribution of fatty acids including conjugated linoleic acids in healthy and cancerous parts of human kidneys. Lipids $\mathbf{4 0}$, $1057-1062$.

38. Mishra GD, McNaughton SA, Bramwell GD, et al. (2006) Longitudinal changes in dietary patterns during adult life. $\mathrm{Br}$ J Nutr 96, 735-744.

39. Pryer JA, Cook A \& Shetty P (2001) Identification of groups who report similar patterns of diet among a representative national sample of British adults aged 65 years of age or more. Public Health Nutr 4, 787-795.

40. McNaughton SA, Mishra GD, Stephen AM, et al. (2007) Dietary patterns throughout adult life are associated with body mass index, waist circumference, blood pressure, and red cell folate. J Nutr 137, 99-105.

41. Varraso R, Fung TT, Barr RG, et al. (2007) Prospective study of dietary patterns and chronic obstructive pulmonary disease among US women. Am J Clin Nutr 86, 488-495.

42. Newby PK, Weismayer C, Akesson A, et al. (2006) Longitudinal changes in food patterns predict changes in weight and body mass index and the effects are greatest in obese women. J Nutr 136, 2580-2587.

43. $\mathrm{Wu} \mathrm{K}, \mathrm{Hu} \mathrm{FB}$, Willett WC, et al. (2006) Dietary patterns and risk of prostate cancer in U.S. men. Cancer Epidemiol Biomarkers Prev 15, 167-171.

44. Perrin AE, Dallongeville J, Ducimetiere P, et al. (2005) Interactions between traditional regional determinants and socioeconomic status on dietary patterns in a sample of French men. Br J Nutr 93, 109-114.

45. Hearty AP \& Gibney MJ (2009) Comparison of cluster and principal component analysis techniques to derive dietary patterns in Irish adults. Br J Nutr 101, 598-608. 